\title{
Desenvolvimento dos órgãos e deposição de gorduras em cabritos Canindé sob restrição alimentar ${ }^{1}$
}

\author{
Development of organs and fat deposition in indigenous goat kids under feed restriction
}

\section{BEZERRA, Andreia Batista ${ }^{2}$; MEDEIROS, Ariosvaldo Nunes de ${ }^{2}$; GONZAGA NETO, Severino $^{2}$; BISPO, Safira Valença ${ }^{2}$; CARVALHO, Francisco Fernando Ramos de ${ }^{3}$; SANTOS NETO, José Maurício dos ${ }^{4}$; SOUZA, Anaiane Pereira ${ }^{4 *}$ RIBEIRO, Luana Paula dos Santos ${ }^{5}$}

\author{
${ }^{1}$ Pesquisa financiada pelo Banco do Nordeste ( BNB). \\ ${ }^{2}$ Universidade Federal da Paraíba, Centro de Ciências Agrárias, Departamento de Zootecnia, Areia, \\ Paraíba, Brasil. \\ ${ }^{3}$ Universidade Federal Rural de Pernambuco, Recife, Pernambuco, Brasil. \\ ${ }^{4}$ Universidade Estadual Paulista, Jaboticabal, São Paulo, Brasil. \\ ${ }^{5}$ Universidade Federal da Bahia, Salvador, Bahia, Brasil. \\ *Endereço para correspondência: anaianesouza@gmail.com
}

\section{RESUMO}

Objetivou-se avaliar o efeito da restrição alimentar sobre o desenvolvimento dos órgãos e deposição de gordura em caprinos Canindé castrados. Foram utilizados 21 cabritos confinados, em um delineamento inteiramente casualizado, com peso inicial de $15,9 \pm 1,03 \mathrm{~kg}$. Os cabritos foram alocados em três níveis de restrição alimentar (sete animais por nível): $a d$ libitum (alimentados à vontade); restrição moderada (restrição de $20 \%$ em relação à quantidade de matéria natural consumida pelos animais alimentados ad libitum) e restrição severa (restrição de $40 \%$ em relação à quantidade de ração consumida pelos animais alimentados ad libitum). A ração experimental apresentou uma proporção de $55 \%$ de volumoso (Tifton) e 45\% de concentrado. Aos 110 dias de experimento os cabritos foram abatidos com peso médio de 23,5 $\mathrm{kg} \pm 2,5 \mathrm{~kg}$. Esvaziou-se o trato gastrointestinal (TGI), a bexiga e a vesícula biliar e foram mensurados os seus pesos para determinação do peso de corpo vazio (PCV). Foram separados e registrados os pesos dos órgãos (baço, coração, fígado, pâncreas, pulmões, rins, sangue, TGI) e dos depósitos de gordura (cardíaca, mesentérica, omental e pélvico-renal). A restrição alimentar em caprinos Canindé afetou o peso absoluto dos órgãos e das gorduras $(P<0.05)$ que estão mais envolvidas com a função de reserva energética (mesentérica, omental e pélvico-renal), no entanto, não afetou o percentual dos órgãos em relação ao $\operatorname{PCV}(P>0.05)$, indicando que mesmo sob restrição o desenvolvimento dos órgãos é proporcional ao desenvolvimento do corpo.

Palavras-chave: adipogênese, alimentação, raça nativa, semiárido

\section{SUMMARY}

The study aimed to evaluate the effect of feed restriction on the development of organs and fat deposition in castrated Caninde goats. Twenty one goats were distributed in a completely randomized design, with initial body weight of $15.9 \pm 1.03 \mathrm{~kg}$. The goats were allocated into three levels of feed restriction (seven animals per level): ad libitum; moderate restriction (restriction of $20 \%$ on the amount of feed consumed by the animals fed ad libitum) and severe restriction $(40 \%$ restriction on the amount of feed consumed by the animals fed ad libitum). The diet consisted of $55 \%$ forage (Tifton) and $45 \%$ concentrate. At 110 days of experiment, the goats were slaughtered with abody weight of $23.5 \mathrm{~kg} \pm 2.5 \mathrm{~kg}$. The components included the internal organs (spleen, heart, liver, pancreas, lungs, kidneys, blood) the emptied and cleaned digestive tract and fat deposits (in heart, 
mesenteric, omental and pelvic-renal) were weighed. Feed restriction in Canindé goats affected the weight of organs and fat deposition in regions more involved with the energy storage function (mesenteric, omental and pelvic-renal) $(\mathrm{P}<0.05)$, however, feed restriction does not affect the percentage of the organs in relation to EBW $(\mathrm{P}>0.05)$, indicating that even under feed restriction organ development is proportional to the development of the body.

Keywords: adipogenesis, feeding, indigenous breed, semi-arid

\section{INTRODUÇÃO}

A produção de caprinos é uma atividade pecuária que contribui para o desenvolvimento socioeconômico de diversas regiões do mundo. No Brasil, o Nordeste compreende a grande maioria do efetivo nacional, onde a criação é baseada em sistemas extensivo ou semiintensivo. Devido à irregularidade na distribuição de chuvas e os períodos prolongados de estiagem na região, a produção de alimentos é sazonal, o que afeta o desenvolvimento dos animais.

Os efeitos da limitação de nutrientes no organismo animal foram estudados por Ryan et al. (1990), que relata que a restrição alimentar impede o animal de expressar seu potencial de crescimento e tem consequências diretas no seu desempenho e na sua composição corporal. Segundo Drouillard et al. (1991), os tecidos são mobilizados sequencialmente na restrição de alimentos a depender das atividades metabólicas que exercem.

Alguns estudos foram conduzidos para avaliar os efeitos da restrição alimentar sobre as características da carcaça caprina (YÁÑEZ et al., 2006; PEREIRA FILHO et al., 2007). Todavia, são poucas as informações das implicações da restrição alimentar sobre os componentes que não fazem parte da carcaça, tornando-se importante entender melhor seus efeitos sobre o desenvolvimento dos órgãos, pois estes são necessários para o funcionamento do organismo. Segundo Jorge et al. (1999), o peso do fígado pode ser reduzido em até $25 \%$ quando os animais passam por restrição alimentar de dois dias, em função de uma provável resposta ao fato de órgãos como fígado, coração, rins, glândula mamária e constituintes do trato gastrointestinal apresentarem intensa atividade metabólica sob situação de produção.

Com base no exposto, objetivou-se avaliar os efeitos da restrição alimentar sobre o desenvolvimento dos órgãos e os depósitos de gordura de caprinos da raça Canindé.

\section{MATERIAL E MÉTODOS}

O experimento foi desenvolvido na estação experimental de pequenos ruminantes, pertencente ao Centro de Ciências Agrárias da Universidade Federal da Paraíba - CCA/UFPB, localizada no município de São João do Cariri, Paraíba, Brasil, microrregião do Cariri Ocidental, entre as coordenadas $7^{\circ} 23^{\prime} 27^{\prime \prime}$ de latitude sul e $36^{\circ} 31^{\prime} 58^{\prime \prime}$ de longitude oeste.

Foram utilizados 21 cabritos castrados da raça Canindé, com aproximadamente cinco meses de idade e peso inicial de $15,9 \mathrm{~kg} \pm 1,03 \mathrm{~kg}$. Os animais foram pesados, identificados, tratados contra ecto e endoparasitas, vacinados contra clostridiose e distribuídos aleatoriamente em baias com área de $3,75 \mathrm{~m}^{2}$ dotadas de comedouros e bebedouros individuais.

Os cabritos foram alocados em três níveis de restrição (sete animais por nível): ad libitum (alimentados à vontade), restrição moderada (restrição 
de $20 \%$ em relação à quantidade de matéria natural consumida pelos animais alimentados ad libitum) e restrição severa (restrição de $40 \%$ em relação à quantidade de ração consumida pelos animais alimentados ad libitum). A ração experimental foi formulada conforme recomendações do NRC (2007), em uma proporção de $55 \%$ de volumoso e $45 \%$ de concentrado, atendendo às exigências nutricionais de cabritos machos castrados para ganho de peso de $0,1 \mathrm{~kg}$ por dia (Tabela 1).

As amostras dos ingredientes da dieta experimental foram analisadas para determinação da matéria seca (MS; AOAC, 2005, método número 930,15), proteína bruta (PB; AOAC, 2005, método número 984,13), extrato etéreo (EE; AOAC, 2005, método número 920,39), cinzas (Cinzas, AOAC, 2005, método número 942,05), fibra em detergente neutro (FDN; MERTENS, 2002) e fibra em detergente ácido (FDA; AOAC, 2005, método número 973,18). A energia bruta (EB) foi determinada usando uma bomba calorimétrica adiabática do tipo Parr.

Os animais permaneceram confinados por aproximadamente 110 dias, quando então foram destinados ao abate, apresentando peso médio de $23,5 \mathrm{~kg} \pm$ $2,5 \mathrm{~kg}$. Antes do abate foram submetidos a jejum de sólidos por um período de 16 horas, em seguida foram pesados para a determinação do peso vivo ao abate (PVA), atordoados por concussão cerebral através de pistola de dardo cativo, suspensos pelos membros posteriores e sangrados através da secção da veia jugular e artéria carótida. Ao transcorrerem quatro minutos após a sangria procedeu-se a esfola, em seguida evisceração e amputações.

Tabela 1. Ingredientes e composição química da ração experimental

\begin{tabular}{lc}
\hline Item & $\mathrm{g} / \mathrm{kg} \mathrm{MS}$ \\
\hline Ingredientes & \\
\hline Feno de tifton & 550,00 \\
Farelo de milho & 281,90 \\
Farelo de soja & 156,40 \\
Suplemento Mineral ${ }^{1}$ & 4,50 \\
Calcário & 7,20 \\
\hline Composição Química & \\
\hline MS (g/kg) & 883,20 \\
Cinzas (g/kg MS) & 63,88 \\
PB (g/kg MS) & 164,66 \\
EE (g/kg MS) & 51,83 \\
FDN (g/kg MS) & 458,68 \\
FDA (g/kg MS) & 254,09 \\
EB (Mcal/kg MS) & 4,23 \\
\hline IComposicão: Ca 7,5\%: P 3\%; Fe 16,500ppm; Mn 9,750ppm; Zn 35,000ppm; I 1000ppm; Co 1000ppm
\end{tabular}

Esvaziou-se o trato gastrointestinal (TGI), a bexiga e a vesícula biliar e em seguida foram mensurados os seus pesos para determinação do peso de corpo vazio (PCV). Foram separados e registrados os pesos dos órgãos (baço, coração, fígado, pâncreas, pulmões, rins, sangue, TGI) e dos depósitos de 
gordura (cardíaca, mesentérica, omental e pélvico-renal). A gordura total foi obtida pelo somatório dos depósitos de gordura. Os órgãos foram expressos em termos absolutos $(\mathrm{kg})$ e em percentual do PCV e os depósitos de gordura foram expressos em termos absolutos $(\mathrm{kg})$.

O delineamento experimental utilizado foi o inteiramente casualizado, com três tratamentos e sete repetições por tratamento, de acordo com o seguinte modelo:

$\mathrm{Yij}=\mu+\mathrm{Si}+$ eij

Em que: $Y i j=$ variável observada; $\mu=$ média geral $\mathrm{Si}=$ efeito do nível de restrição; eij = erro aleatório associado a cada observação.
Os dados foram submetidos à análise de variância e as médias comparadas pelo teste de Tukey a $5 \%$ de probabilidade através do programa Statistical Analysis System (SAS, 1999).

\section{RESULTADOS E DISCUSSÃO}

Observou-se que os animais alimentados ad libitum apresentaram PVA e PCV mais elevados (Tabela 2) em decorrência da maior ingestão de MS (720g/dia em animais alimentados ad libitum e 440g/dia quando alimentados na restrição de $40 \%$ ) e consequentemente maior deposição de tecidos.

Tabela 2. Peso de órgãos de caprinos Canindé submetidos à restrição alimentar

\begin{tabular}{lcccrc}
\hline \multirow{2}{*}{ Variáveis (kg) } & \multicolumn{3}{c}{ Restrição Alimentar } & ${ }^{5} P$ & ${ }^{6} \mathrm{EPM}$ \\
\cline { 2 - 4 } & Ad libitum & Restrição moderada & Restrição severa & & \\
\hline${ }^{1} \mathrm{CMS}(\mathrm{kg} /$ dia) & $0,74^{\mathrm{a}}$ & $0,56^{\mathrm{b}}$ & $0,44^{\mathrm{c}}$ & 0,0001 & 0,014 \\
${ }^{2} \mathrm{PVA}$ & $24,23^{\mathrm{a}}$ & $21,45^{\mathrm{b}}$ & $19,07^{\mathrm{c}}$ & 0,0001 & 0,538 \\
${ }^{3} \mathrm{PCV}$ & $21,27^{\mathrm{a}}$ & $18,71^{\mathrm{b}}$ & $16,21^{\mathrm{c}}$ & 0,0001 & 0,480 \\
Sangue & $0,96^{\mathrm{a}}$ & $0,82^{\mathrm{b}}$ & $0,67^{\mathrm{c}}$ & 0,0001 & 0,037 \\
Fígado & $0,44^{\mathrm{a}}$ & $0,36^{\mathrm{b}}$ & $0,29^{\mathrm{c}}$ & 0,0001 & 0,014 \\
Rins & $0,08^{\mathrm{a}}$ & $0,07^{\mathrm{b}}$ & $0,06^{\mathrm{b}}$ & 0,0033 & 0,002 \\
Coração & $0,10^{\mathrm{a}}$ & $0,09^{\mathrm{b}}$ & $0,08^{\mathrm{b}}$ & 0,0004 & 0,002 \\
Pulmões & $0,19^{\mathrm{a}}$ & $0,16^{\mathrm{a}}$ & $0,12^{\mathrm{b}}$ & 0,0006 & 0,095 \\
Baço & $0,04^{\mathrm{a}}$ & $0,03^{\mathrm{a}}$ & $0,02^{\mathrm{b}}$ & 0,0010 & 0,001 \\
Pâncreas & 0,0358 & 0,0325 & 0,0295 & 0,6520 & 0,002 \\
${ }^{4}$ TGI & $1,39^{\mathrm{a}}$ & $1,23^{\mathrm{ab}}$ & $0,99^{\mathrm{b}}$ & 0,0220 & 0,062 \\
\hline
\end{tabular}

Médias seguidas de letras diferentes nas linhas diferem entre si pelo teste de Tukey a $5 \%$ de probabilidade; ${ }^{1}$ Consumo de matéria seca; ${ }^{2}$ Peso vivo ao abate; ${ }^{3}$ Peso de corpo vazio; ${ }^{4}$ Trato gastrointestinal; ${ }^{5} P=$ significância; ${ }^{6} \mathrm{EPM}=$ erro padrão da média.

Com a restrição alimentar ocorreu redução no peso do sangue, fígado e rins. Da mesma forma, Moyo et al. (2011) encontraram menor peso de fígado $(0,259 \mathrm{~kg})$ e rins $(0,041 \mathrm{~kg})$ em caprinos cruzados Xhosa lop-eared que ingeriram menor quantidade de MS, bem como Liméa et al. (2009) em caprinos inteiros da raça Creolo sob restrição de concentrado $(0,30 \mathrm{~kg}$ para o fígado e $0,053 \mathrm{~kg}$ para os rins). Os animais alimentados ad libitum apresentaram maior peso de coração (Tabela 2), entretanto, contrário ao 
padrão observado no sangue e no peso de corpo vazio, não foi observada diferença entre os animais da restrição moderada e da restrição severa. Martins et al. (2014) encontraram resultados semelhantes ao avaliarem o efeito de três níveis de restrição alimentar em caprinos das raças Canindé, Moxotó e mestiços $1 / 2$ Boer X $1 / 2$ SPRD (sem padrão racial definido). Os valores encontrados nesta pesquisa também foram semelhantes aos reportados por Yilmaz et al. (2010) e Rodrigues et al. (2013). Dessa forma, a redução de alimentos afetou o desenvolvimento dos órgãos quando avaliados em unidades de peso absoluto, todavia o mesmo não foi observado para os dados quando tratados em unidades de peso relativo ao PCV.

Os pesos dos pulmões foram semelhantes entre animais alimentados ad libitum $(0,19 \mathrm{~kg})$ e da restrição moderada $(0,16 \mathrm{~kg})$ e inferiores em animais submetidos à restrição severa $(0,12 \mathrm{~kg})$. O mesmo comportamento foi observado para os valores de peso de baço, em que os pesos foram semelhantes entre animais alimentados ad libitum $(0,04 \mathrm{~kg})$ e da restrição moderada $(0,03 \mathrm{~kg})$, e inferiores em animais submetidos à restrição severa $(0,02 \mathrm{~kg})$. Já o peso do pâncreas, responsável pela síntese de importantes hormônios metabólicos, diferentemente do esperado, não foi afetado pela restrição alimentar. Lisboa et al. (2010), avaliando dois níveis de ingestão de energia, observaram diferença para o peso do pâncreas e semelhança para o pesos dos pulmões e baço de caprinos da raça Canindé e Moxotó, cujos valores reportados variaram de 0,18 a $0,17 \mathrm{~kg}$ nos pulmões; 0,05 a $0,03 \mathrm{~kg}$ no pâncreas e 0,03 a $0,02 \mathrm{~kg}$ no baço.

Os animais alimentados ad libitum apresentaram maior peso do TGI quando comparados aos da restrição severa (Tabela 2), o que pode ser justificado pelo maior consumo de matéria seca (CMS) ter ocasionado maior distensão física no TGI. O mesmo foi encontrado por Mattos et al. (2006) ao avaliarem o efeito da restrição alimentar sobre os órgãos de cabritos Canindé e Moxotó, na fase de recria, abatidos com idade e peso semelhantes aos caprinos do presente estudo. Esses autores reportaram peso de $1,09 \mathrm{~kg}$ de TGI nos animais alimentados ad libitum, valor inferior ao encontrado para animais alimentados ad libitum desta pesquisa $(1,39 \mathrm{~kg})$, o que pode ser atribuído às diferenças na relação volumoso concentrado utilizada entre os dois experimentos (40:60 pelos referidos autores e 55:65 nesta pesquisa). A maior ingestão de volumoso está atrelada a uma maior capacidade de armazenamento e de posterior fermentação, portanto animais que ingerem mais alimento volumoso tendem a apresentar um maior desenvolvimento de rúmen (RESENDE JUNIOR et al., 2006).

Quando expressos em percentual do PCV (Tabela 3), os pesos dos órgãos avaliados não diferiram entre os níveis de restrição, sugerindo que o tamanho dos órgãos é proporcional ao tamanho do animal, sendo essa, provavelmente, uma adaptação para o atendimento das funções fisiológicas vitais. Estes resultados estão de acordo com reportado por Ferrell (1988) que ao pesquisar a contribuição das vísceras sobre o desprendimento de energia, relatou que $o$ peso dos órgãos tem relação direta com o ganho em peso dos animais que estão em fase de crescimento.

O termo rusticidade que é empregado frequentemente para raças nativas $\mathrm{e}$ naturalizadas, é relacionado à capacidade de manter as atividades básicas do organismo mesmo diante de 
situações de estresse por calor por exemplo. Ainda em relação à capacidade de manutenção das atividades básicas, Souza et al. (2014) obtiveram valores para exigências líquidas de energia para mantença de caprinos Canindé inferiores aos relatados para outras raças. $\mathrm{O}$ peso dos órgãos tem relação direta com energia utilizada para mantença uma vez que representam o maior custo destinado para a mantença no organismo (FERRELL, 1988). No presente estudo, os pesos de órgãos em animais alimentados ad libitum foram inferiores aos pesos em animais alimentados ad libitum, castrados, com pesos semelhantes, mas representantes de raças utilizadas na produção de carne (CAMERON et al., 2001; El-WAZIRY et.al., 2011).

Tabela 3. Percentual do peso dos órgãos em relação ao ${ }^{1} \mathrm{PCV}$ de caprinos Canindé submetidos à restrição alimentar

\begin{tabular}{|c|c|c|c|c|c|}
\hline \multirow{2}{*}{$\begin{array}{l}\text { Variáveis } \\
\% \text { de PCV }\end{array}$} & \multicolumn{3}{|c|}{ Restrição Alimentar } & \multirow{2}{*}{${ }^{3} P$} & \multirow{2}{*}{${ }^{4} \mathrm{EPM}$} \\
\hline & Ad libitum & Restrição moderada & Restrição severa & & \\
\hline Sangue & 4,53 & 4,52 & 4,16 & 0,2998 & 0,001 \\
\hline Fígado & 2,05 & 1,92 & 1,79 & 0,0635 & 0,049 \\
\hline Rins & 0,37 & 0,35 & 0,37 & 0,7519 & 0,012 \\
\hline Coração & 0,46 & 0,46 & 0,48 & 0,4664 & 0,007 \\
\hline Pulmões & 0,94 & 0,88 & 0,75 & 0,1467 & 0,040 \\
\hline Baço & 0,17 & 0,18 & 0,16 & 0,3458 & 0,004 \\
\hline Pâncreas & 0,17 & 0,17 & 0,19 & 0,9050 & 0,014 \\
\hline${ }^{2} \mathrm{TGI}$ & 6,54 & 6,59 & 6,02 & 0,7031 & 0,306 \\
\hline
\end{tabular}

Verificou-se que os cabritos alimentados ad libitum apresentaram maior deposição de gordura total, pélvico renal, mesentérica e omental quando comparados aos cabritos submetidos à restrição severa, enquanto que os da restrição moderada demonstraram deposição intermediária (Tabela 4). A menor deposição de gordura em animais submetidos à restrição pode ser explicada pelo menor consumo de energia, haja vista que a exigência energética para a lipogênese é elevada. Em outros estudos também foi verificada menor deposição de lipídeos em função da redução na ingestão de energia (BEZERRA et al., 2010; LISBOA et al., 2010; MARQUES et al.,
2014). Mesmo em condição de restrição alimentar, os caprinos Canindé apresentaram deposição de gordura total no corpo superior à deposição em caprinos castrados da raça Saanen com pesos semelhantes (FIGUEIREDO, 2014), o que pode demonstrar a reserva energética como prioridade para as raças nativas e naturalizadas.

Uma maior deposição de gorduras em raças nativas e naturalizadas também está atrelada a menores valores de energia líquida para mantença. Os gastos energéticos para manutenção de tecido adiposo são inferiores que os gastos para manter tecido muscular (GILL et al., 1989). Dessa forma, caprinos nativos apresentam 
Rev. Bras. Saúde Prod. Anim., Salvador, v.17, n.1, p.55-64 jan./mar., $2016 \quad$ http://www.rbspa.ufba.br

desenvolvimento dos órgãos $\mathrm{e}$ deposição de gordura favoráveis a situações de escassez de alimentos, em que a gordura cavitária é o maior depósito de gorduras e atua como reserva energética. Assim sendo, tais informações são importantes por influenciarem as exigências de energia para mantença do animal (BACKES et al., 2010). Por outro lado a energia que é priorizada na deposição de tecido adiposo também tem importância na análise do rendimento de carcaça, uma vez que a quantidade de carne magra é o que mais interessa na produção de carne.

$\mathrm{O}$ peso da gordura cardíaca não foi afetado pelos níveis de restrição alimentar (Tabela 4), demonstrando que, na região do pericárdio, a deposição de gordura cardíaca (envolvida com a proteção do coração) é pouco influenciada por fatores alimentares, o que pode estar associado à funcão na referida região. $\mathrm{O}$ mesmo foi relatado por Mushi et al. (2009), quando também não observaram influência da restrição de concentrado sobre a gordura cardíaca de caprinos castrados da raça Small East African. Estrategicamente a deposição das gorduras omental, mesentérica e renal é relevante para períodos em que a energia ingerida não é suficiente para suprimento das necessidades dos animais, dessa forma, a energia armazenada na forma de gordura pode ser utilizada para o metabolismo principalmente dos órgãos que compreendem o trato gastrointestinal e que correspondem à maior demanda energética do organismo.

Tabela 4. Depósitos de gordura em caprinos Canindé submetidos à restrição alimentar

\begin{tabular}{lcccrrr}
\hline \multirow{2}{*}{ Variáveis $(\mathrm{kg})$} & \multicolumn{3}{c}{ Restrição } & ${ }^{2} P$ & ${ }^{3} \mathrm{EPM}$ \\
\cline { 2 - 4 } & Ad Libitum & Restrição & Restrição & & & \\
\hline${ }^{1}$ Gordura total & $1,90^{\mathrm{a}}$ & $1,64^{\mathrm{ab}}$ & $1,11^{\mathrm{b}}$ & & 0,0066 & 0,112 \\
Gordurapélvico-renal & $0,544^{\mathrm{a}}$ & $0,472^{\mathrm{ab}}$ & $0,238^{\mathrm{b}}$ & & 0,0253 & 0,050 \\
Gordura omental & $0,872^{\mathrm{a}}$ & $0,730^{\mathrm{ab}}$ & $0,515^{\mathrm{b}}$ & 0,0174 & 0,054 \\
Gorduramesentérica & $0,382^{\mathrm{a}}$ & $0,338^{\mathrm{ab}}$ & $0,272^{\mathrm{b}}$ & 0,0356 & 0,018 \\
Gordura cardíaca & 0,103 & 0,101 & 0,085 & 0,3597 & 0,005 \\
\hline
\end{tabular}

Médias seguidas de letras diferentes nas linhas diferem entre si pelo teste de Tukey a $5 \%$ de probabilidade; ${ }^{1}$ gordura total $=$ gordura mesentérica + gordura omental + gordura cardíaca + gordura pélvica- renal; ${ }^{2} P=$ significância; ${ }^{3} \mathrm{EPM}=$ erro padrão da média.

A condição de restrição alimentar em caprinos Canindé afetou o peso absoluto dos órgãos e das gorduras que estão mais envolvidas com a função de reserva energética (mesentérica, omental e pélvico-renal), no entanto, não afetou o percentual dos órgãos em relação ao PCV. O desenvolvimento dos órgãos e a deposição de gordura em caprinos nativos conferem melhor adaptação diante da escassez de alimentos e redução dos gastos energéticos.

\section{AGRADECIMENTOS}

Os autores gostariam de agradecer ao Conselho Nacional de Desenvolvimento Científico e Tecnológico (CNPq) e ao Banco do Nordeste pelo aporte financeiro. 
Rev. Bras. Saúde Prod. Anim., Salvador, v.17, n.1, p.55-64 jan./mar., $2016 \quad$ http://www.rbspa.ufba.br ISSN 15199940

\section{REFERÊNCIAS}

ASSOCIATION OF OFFICIAL ANALYTICAL CHEMISTS - AOAC. Official Methods of Analysis. 18. ed. Washington, D.C, 2005.

BACKES, A.A.; PAULINO, M.F.; ALVES, D.D.; VALADARES FILHO, S.C. Tamanho relativo dos órgãos internos e do trato gastrintestinal de bovinos Indubrasil e mestiços leiteiros em fase de engorda. Ciência Rural, v.40, n.5, p.1160-1165, 2010.

BEZERRA, S.B.L.; VERAS, A.S.C.; SILVA, D.K.A., FERREIRA, M.A.; PEREIRA, K.P.; ALMEIDA, J.S.; SANTOS, J.C.A. Componentes não integrantes da carcaça de cabritos alimentados em pastejo na Caatinga. Pesquisa Agropecuária Brasileira, v.45, n.7, p.751-757, 2010.

CAMERON, M.R.; LUO, J.; SAHLU, T.; HART, S.P.; COLEMAN, S.W.; GOETSCH, A.L. $t$ Growth and slaughter traits of Boer x Spanish, Boer $\mathrm{x}$ Angora, and Spanish goats consuming a concentrate-based diet. Journal of Animal Science, v.79, p.1423-1430, 2001.

DROUILLARD, J.S.; KLOPFENSTEIN, T.J.; BRITTON, R.A.; GRAMLICH, S.M.; WESTER, T.J.; FERRELL, C.L.Growth, body composition and visceral organ mass and metabolism in lambs during and after metabolizable protein or net energy restriction. Journal of Animal Science, v.69, p.3357-3375, 1991.

El-WAZIRY, A.M; AL-OWAIMER, A.N.; SULIMAN G.M.; HUSSEIN, E.S.; ABOUHEIF, M.A. Performance, carcass characteristics and meat quality of intact and castrated Ardhi goat kids fed high energy diet. Journal of Animal and Veterinary Advances, v.10, n.16, p.2157-2162, 2011.

FERRELL, C. L. Contribution of visceral organs to animal energy expenditures. Journal of Animal Science, v.66, n.3, p.23-24, 1988.

FIGUEIREDO, F.O.M. Energy and protein requirements of male and female Saanen goats between 15 and 30 kg body weight. $2014.81 \mathrm{p}$. Tese (Doutorado) - Universidade Estadual de São Paulo, Jaboticabal.

GILL, M; FRANCE, J.; SUMMERS, M.; MCBRIDE, B.W.; MILLIGAN, P.L. Simulation of the Energy Costs Associated with Protein Turnover and $\mathrm{Na}+, \mathrm{K}+-$ Transport in Growing Lambs. Journal of Nutrition, v.119, n.9, p.12871299, 1989.

JORGE, A.M.; FONTES, C.A.A.; PAULINO, M.F.; GOMES JÚNIOR, P. Tamanho relativo dos órgãos internos de zebuínos sob alimentação restrita e "ad libitum". Revista Brasileira de Zootecnia, v.28, n.2, p.374-380, 1999.

LIMÉA, L.; BOVAL M.; MANDONNET N.; GARCIA, G.; ARCHIMÈDE, H.; ALEXANDRE, G. Growth performance, carcass quality, and noncarcass components of indigenous Caribbean goats under varying nutritional densities. Journal of Animal Science, v.87, n.11, p.3770-3781, 2009.

LISBOA, A.C.C.; FURTADO, D.A.; MEDEIROS, A.N.; COSTA, R.G.; QUEIROGA, R.C.E.; BARRETO, L.M.G. Quantitative characteristics of the carcasses of Moxotó and Canindé goats fed diets with two diferente energy levels. Revista Brasileira de Zootecnia, v.39, n.7, p.1565-1570, 2010. 
Rev. Bras. Saúde Prod. Anim., Salvador, v.17, n.1, p.55-64 jan./mar., $2016 \quad$ http://www.rbspa.ufba.br ISSN 15199940

MARQUES, C.A.T.; MEDEIROS, A.N.; COSTA, R.G.; CARVALHO, F.F.R.; ARAÚJO, M.J.; TORREÃO, J.N.C. Performance and carcass traits of Moxotó growing goats supplemented on native pasture under semiarid conditions. Revista Brasileira de Zootecnia, v.43, n.3 p.151-159, 2014.

MARTINS, S.R.; CHIZZOTTI M.L.; YANAMOTO, S.M.; RODRIGUES, R.T.; BUSATO K.C.; SILVA, T.S.Carcass and non-carcass component yields of crossbred Boer and Brazilian semiarid indigenous goats subjected to different feeding levels. Tropical animal health and production, v.46, n.4, p.647-653, 2014.

MATTOS, C.W.; CARVALHO, F.F.R.; DUTRA JÚNIOR, W.M.; VÉRAS, A.S.C.; BATISTA, A.M.V.; ALVES, K.S.; RIBEIRO, V.L.; SILVA, M.J.M.S.; MEDEIROS, G.R.; VASCONCELOS, R.M.J.; ARAÚJO, A.O.; MIRANDA, S.B.Characteristics of carcass and non-carcass components of Moxotó and Canindé male kids under two feeding levels. Brazilian Journal of Animal Science, v.35, n.5, 21252131, 2006.

MERTENS, D.R. Gravimetric determination of amylase-treated neutral detergent fibre in feeds with refluxing beakers or crucibles: collaborative study. Journal of AOAC international, v.85, n.6, p.1217-1240, 2002.

MOYO, B.; MASIKA, P.J.; MUCHENJE, V.Effect of supplementing crossbred Xhosa lopeared goats castrates with Moringa oleifera leaves on growth performance, carcass and non-carcass characteristics. Tropical Animal Health and Production, v.44, n.4, p. 801-809, 2011.
MUSHI, D.E.; SAFARI, J.; MTENGA, L.A.; KIFARO, G.C.; EIK, L.O.

Growth and distribution of non-carcass components of Small East African and F1 Norwegian crossbred goats under concentrate diets. Livestock Science, v.126, p.80-86, 2009.

NATIONAL RESEARCH COUNCIL NRC. Nutrient requeriments of small ruminants. 7. ed. Washington, D.C, 2007.

PEREIRA FILHO, J.M.; RESENDE, K.T.; TEIXEIRA, I.A.M.A.; SILVA SOBRINHO, A.G.; YAÑEZ, E.A.; FERREIRA, A.C.D. Efeito da restrição alimentar sobre algumas características de carcaça de cabritos F1 Boer X Saanen. Revista Ciência e Agrotecnologia, v.31, n.2, p.499-505, 2007.

RESENDE-JUNIOR, J.C.; ALONSO, L.S; PEREIRA, M.N; MAGALLANES, M.G.R.; DUBOC, M.V.; OLIVEIRA, E.C.; MELO, L.Q. Effect of the feeding pattern on rumen wall morphology of cows and sheep. Brazilian Journal of Veterinary Research and Animal Science, v.43, n.4, p.526-536, 2006.

RODRIGUES, L.; GONÇALVES, H.C.; MEDEIROS, B.B.L.; MENEZES, J.J.L.; MAESTÁ, S.A. Avaliação da somatotropina bovina recombinante (RBST) nos não-componentes da carcaça de cabritos de três genótipos. Ciência Animal Brasileira, v.14, n.2, p.143-150, 2013.

RYAN, W.J.; WILLIAMS, I.H.; MOIR, R.J. Compensatory growth in cattle and sheep. Nutrition Abstract Review Series B. Livestock Feeds and Feeding, v.60, n.9, p.653-664, 1990. 
SAS. Statistical Analysis System

Introductory Guide for Personal

Computers. Release. Cary, NC: Sas

Institute Inc., 1999.

SOUZA, A.P.; MEDEIROS, A.N.;

CARVALHO, F.F.R.; COSTA, R.G.;

RIBEIRO, L.P.S.; BEZERRA, A.B.;

BRANCO, G.L.C.; SILVA JR., C.G.

Energy requirements for maintenance

and growth of Canindé goat kids. Small

Ruminant Research, v.121, p.255-261, 2014.

YÁÑEZ, E.A.; RESENDE, K.T.; FERREIRA, A.C.D.; MEDEIROS, A.N.; SILVA SOBRINHO, A.G.; ARTONI, S.M.B.Effects of feed restriction on yield, retail cuts and tissue composition of carcass of Saanen kids. Brazilian Journal of Animal Science, v.36, n.3, p.666-673, 2007.

YILMAZ, A.; EKIZ, B.; OZCAN, M.; KAPTAN, C.; HANOGLU, H.; YILDIRIR, M.; KOCAK, O.Carcass quality characteristics of Hair goat and Saanen $\times$ Hair goat crossbred kids from intensive production system. Journal of Animal and Feed Science, v.19, n.3, p. 368-378, 2010.

Data de recebimento: 10/03/2015

Data de aprovação: 19/02/2016 